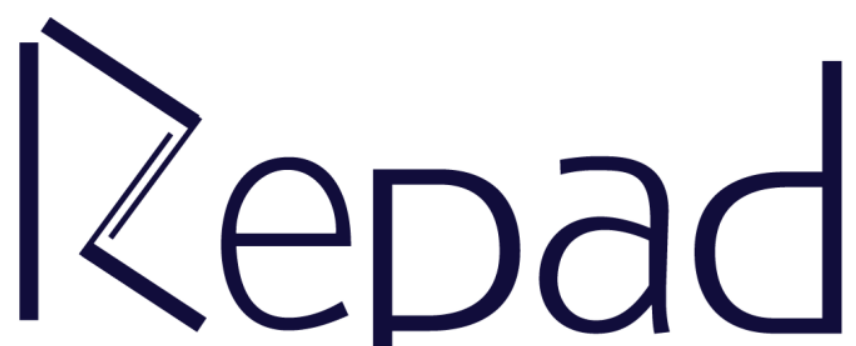

v. 5, n. 1, Janeiro-Abril/2021

Revista Estudos e

Pesquisas em Administração

(c) (i) This work is licensed under a Creative Commons Attribution 4.0 International License 


\title{
Avaliação de veículos utilizados na distribuição urbana de mercadorias na perspectiva do bem-estar da população
}

\author{
Cesar Eduardo Leite \\ cesareleite@hotmail.com \\ ORCID: 0000-0002-6144-7733 \\ Programa de Pós-Graduação em Transportes, Universidade de Brasília \\ Brasília, Distrito Federal, Brasil \\ Sérgio Ronaldo Granemann \\ ORCID: 0000-0001-8772-798X \\ Programa de Pós-Graduação em Transportes, Universidade de Brasília \\ Brasília, Distrito Federal, Brasil \\ João Carlos Félix Souza \\ ORCID: 0000-0002-9883-8148 \\ Faculdade de Tecnologia, Universidade de Brasília \\ Brasília, Distrito Federal, Brasil
}

\begin{abstract}
RESUMO
O crescimento das cidades e a valorização do conforto de seus habitantes determina um trade-off que pondera entre o transporte urbano de mercadorias, possível gerador de desconforto, e o bem-estar da população. A utilização correta de insumos, inputs, e a efetiva entrega de produtos, outputs, determinam a eficiência, cuja comparação entre seus pares indica o benchmarking. Os outputs representam a perfeita realização dos resultados esperados do processo de transporte urbano de mercadorias, enquanto os inputs representam a tolerância da população aos impactos negativos causados ao seu bem-estar. A pesquisa se utiliza da análise envoltória de dados para avaliar os veículos utilizados no transporte urbano de mercadorias, e indica como benchmarking aquele que promova menores desconfortos aos moradores. Como resultado, são identificados os veículos mais eficientes por realizarem a sua atividade mantendo o bem-estar da população.
\end{abstract}

Palavras-chave: Logística Urbana; Análise Envoltória de Dados; Incomodidades da População.

\section{Evaluation of vehiches used in urban distribution of goods in the perspective of population well-being}

\begin{abstract}
The growth of cities and valuing of its inhabitants' comfort determine a trade-off that consider between urban freight transport, possible discomfort generator, and the population well-being. The appropriate use of raw materials (inputs) and the effective delivery of products (outputs) determine efficiency, which indicates benchmarking after peer comparinson. The outputs represent the perfect realization of expected results of the urban goods transport process, while the inputs represent the population's tolerance to the negative impacts caused to their well-being. The research uses the data
\end{abstract}


envelopment analysis to evaluate the vehicles used in urban goods transport, and indicates as benchmarking the one that promotes the least discomfort to residents. As results, the most efficient vehicles are identified for carrying out their activity while maintaining the population well-being.

Keywords: Urban Logistics; Data Envelopment Analysis; Population Discomforts.

Submetido: 30/10/2020

Aceito: 30/12/2020

Publicado: 30/04/2021

\section{CONSIDERAÇÕES INICIAIS}

Durante todo o Século XX os princípios da Administração Científica difundiram o lema de se "produzir mais com menos" nas indústrias, e a fórmula básica da produção orientou seu resultado como sendo o avaliador do desempenho empresarial da época (Taylor, 2011). A força da produção é definida como a razão entre aquilo que se produz, os outputs, sobre tudo aquilo que tenha sido utilizado para se produzir, os inputs, e é definida como produtividade (Slack, Chambers \& Johnston, 2011). Nesse período, com o desenvolvimento da industrialização, surge a competição entre as empresas, onde aquela que produz a maior quantidade com o menor custo é considerada a mais economicamente eficiente (Mankiw, 2013).

As empresas mais eficientes são consideradas referência para suas concorrentes, as quais deveriam buscar estratégias para alcançar o mesmo nível. Surge, então, o conceito de Benchmarking, que consiste na comparação de processos empresariais, identificando as melhores práticas utilizadas, as quais se configuram como meta para os processos que não alcançaram esse estágio (Ferreira \& Gomes, 2009).

O conceito de eficiência, nesta pesquisa, se baseia naquele utilizado pelo método de Análise Envoltória de Dados (Data Envelopment Analysis - DEA) (Farrell, 1957; Charnes, Cooper \& Rhodes, 1978; Banker, Charnes \& Cooper, 1984), que utiliza o conceito de benchmark para delimitação de uma linha de eficiência dentre as relações inputs - outputs avaliadas. São analisados os veículos transportadores de mercadorias utilizados e identificados aqueles que geram menores desconfortos para a população da cidade de São Paulo, determinando-os como Benchmarking para os demais.

Utilizando-se de um conceito mais elementar, um veículo representa qualquer meio utilizado para transportar ou conduzir pessoas, animais ou volumes, de um lugar para outro. No caso, os veículos avaliados são os meios utilizados para o Transporte Urbano de Mercadorias - TUM, como as entregas de fast food, do e-commerce, entregas de diversas lojas de departamentos, mensageiros e correios, e tantos outros modelos de distribuição de mercadorias na área urbana.

$\mathrm{O}$ desenvolvimento de processos industriais e comerciais mais produtivos, associados ao aumento do consumo e a geração de renda, promovem uma contínua concentração nas áreas urbanas. A vida na cidade atrai mais população e a necessidade de mais insumos, o que resulta em maior número de viagens para o TUM e mais pessoas circulando, mais veículos, mais poluição, e maior desconforto para essa população. Na realidade do Brasil, essa concentração da população nas cidades faz com 
que a população urbana chegue a ser nove vezes maior que a população rural (Brito \& Pinho, 2016).

Para que a população receba os insumos que necessita precisa aceitar o desconforto gerado pelo transporte mercadorias, e renunciar a parte do seu bem-estar. É um trade-off que determina a escolha da solução de um problema em detrimento de outro, e aqui, esse trade-off pondera entre o benefício e o desconforto gerado pelo TUM (Mankiw, 2013).

A logística urbana estuda os serviços de transporte de mercadorias no ambiente urbano (Taniguchi, Thompson, Yamada \& Van Duin, 2001), e tem a eficiência como a maior produtividade nas entregas, segundo a visão econômica. Assim, a logística urbana tem se dedicado a fazer as mercadorias chegarem ao seu destino e proporcionar o BemEstar da População - BEP através de suas necessidades de insumos atendidas, sem avaliar o desconforto gerado por sua atividade.

A pesquisa se propõe a complementar a estratégia do TUM, baseado na produtividade, com a avaliação do BEP, e pondera dentre os meios de transporte utilizados, aqueles que geram menor desconforto para a realização dos serviços de transporte de mercadorias no ambiente urbano. Para identificar os fatores que determinam o BEP, é estudado o Plano Diretor de São Paulo (São Paulo, 2014), onde se definem as situações indesejáveis que geram desconforto a todos, definidas como incomodidades (Araújo Junior, 2005).

O objetivo da pesquisa é avaliar a eficiência dos veículos usados no TUM na cidade de São Paulo, segundo os fatores que impactam negativamente no bem-estar da população, baseados em seu Plano Diretor Estratégico - PDE. Para isso, utiliza-se a Análise Envoltória de Dados - DEA para se calcular a eficiência de cada veículo selecionado.

Na utilização do DEA, os veículos são designados como as Decision Making Units - DMU's (Unidades Tomadoras de Decisão), que oferecem os resultados esperados de um bom serviço de TUM, os outputs, com a utilização do desgaste do BEP provocado pelos impactos negativos gerados pelo TUM, os inputs. Para aplicação do método DEA é utilizado o software SIAD - Sistema Integrado de Apoio à Decisão (Meza, Biondi Neto, Mello \& Gomes, 2005), ferramenta que atende plenamente às necessidades.

Os resultados comprovam que, quando são utilizados os veículos de grande porte para o TUM, esses contribuem negativamente para o BEP da cidade de São Paulo. Dentre os veículos mais eficientes está a bicicleta, que vem sendo tema de muitas pesquisas sobre as vantagens de seu uso na logística urbana.

\section{BASES TEÓRICAS}

\section{Logística Urbana}

Com o TUM se configurando como essencial para a civilização urbana moderna, as cidades pelo mundo têm se preocupado com a distribuição urbana de mercadorias como forma de resolver seus problemas locais de abastecimento. O próprio conceito prevê que a urbanização tenha um sistema de transporte que deva sustentá-la, que atenda as pessoas concentradas em áreas distantes das fontes de insumos, as quais necessitam da logística para equacionar suas necessidades e o volume de mercadorias em trânsito (Ogden, 1992; Dutra, 2004). 
A expressão "logística urbana", assim como o conceito de "city logistics", surgiu com o trabalho de Taniguchi et al. (2001), como sendo o processo de otimização das atividades de logística em áreas urbanas, considerando fatores como tráfego, congestionamento e consumo de energia. City logistics se tornou um termo comum para os mercados urbanos, que representa um sistema de movimento e distribuição física de mercadorias feita essencialmente por meios alternativos (Smirlis, Zeimpekis \& Kaimakamis, 2012).

Apesar da utilização de outros diversos termos, como: "logística urbana", "transporte de carga urbana", "distribuição de carga urbana", "entrega de mercadoria urbana", o termo "logística das cidades", de Taniguchi et al. (2001), define o conceito essencial. Em Ballou (2006), observa-se que o termo tem mais afinidade com o conceito de Distribuição Física das mercadorias, subdivisão da Cadeia de Suprimentos, que é responsável por fazer chegar ao cliente final todos os produtos das operações empresariais.

Percebe-se que o TUM tem papel significativo na competitividade de uma região e é essencial para sua economia, pois gera renda e emprego para a população através dos serviços prestados às indústrias e comércios. A movimentação de mercadorias é parte do processo econômico que disponibiliza produtos para serem utilizados, processados, armazenados ou consumidos, agregando-lhes um valor econômico espacial (Dutra, 2004).

Estudos mostram que, os atuais veículos usados no TUM são responsáveis pelo maior impacto no estudo dos congestionamentos urbanos, e sua exclusão desse meio traria consideráveis ganhos (Cintra, 2014). O transporte de cargas aparece como o problema mais perceptível e determinante para a falta de mobilidade e do bem-estar da população das cidades, apesar de fundamental para o seu desenvolvimento econômico.

No planejamento para a mobilidade urbana sustentável, o conceito de city logistics não se limita ao estudo dos veículos utilizados ou do transporte de mercadorias em áreas urbanas, mas busca uma visão ampla da distribuição física de mercadorias nas cidades (Smirlis et al., 2012). Dentre as diversas iniciativas voltadas ao conceito de city logistics, Gammelgaard (2015) relata a experiência do Citylogistik-kbh, que busca uma visão integrada do movimento de mercadorias na cidade de Copenhagen (Dinamarca), através de um centro de distribuição localizado fora da área urbana, que consolida todas as entregas e utiliza somente carros elétricos para os serviços de distribuição.

\section{Bem-Estar da População}

$\mathrm{O}$ conceito de bem-estar tem visões diferenciadas, desde refletir o estado de saúde de uma pessoa, de seu conforto, até a simples sensação de felicidade. Ao se considerar que o TUM prejudica a mobilidade da população, restringindo deslocamentos, gerando poluição do ar, sonora e até dos cursos de água na região urbana, isto o define como um fator de privação do bem-estar da população em quaisquer perspectivas. Assim, esta pesquisa adota o conceito de bem-estar como a falta de impactos negativos sentidos pela população, sendo maior o bem-estar quanto menor o grau ou incidência de fatores negativos.

Considera-se que a preocupação com o bem-estar da população de uma cidade é dever do Poder Público Municipal, que, através de seu Plano Diretor, deve definir exatamente qual a destinação de uso e ocupação do solo como forma de mitigar que os interesses divergentes gerem desconfortos. Assim, o morador local pode se sentir incomodado quando os limites das atividades desenvolvidas são ultrapassados, pode 
questionar as autoridades e pedir soluções sobre os desconfortos gerados (Dorneles, 2015).

A Lei Federal $n^{\circ} 10.257$ de 10 de julho de 2001 (Brasil, 2001), aprovou o Estatuto da Cidade que define regras para a gestão das áreas urbanas do país, institui diretrizes e instrumentos para garantir a função social da propriedade e define como obrigatória a criação de um Plano Diretor por todos os municípios, os quais devem ser construídos com a participação popular, garantindo o acesso de todos (Araújo Junior, 2005).

O Plano Diretor e o zoneamento das cidades têm a obrigação definir de forma diferenciada: limites de horário e intensidade na emissão de sons e ruídos; limites para emissão de gases poluentes; limites e restrições ao tráfego de veículos; diretrizes para o uso e ocupação do solo e reivindicações que possam ser levantadas pela população (Brasil, 2001).

A pesquisa utiliza a Lei ${ }^{\circ} 13.885$, de 25 de agosto de 2004, que estabelece o Plano Diretor Estratégico da cidade de São Paulo e de suas Subprefeituras (São Paulo, 2014), determinando zonas com limitação sobre as atividades praticadas, tais como, residencial, comercial, industrial, agrícola, e outras; e, ainda, regulamentando a permissão ou proibição da atividade desenvolvida com base no nível de ruído, vibração, emissão de poluentes e no uso do sistema viário (Martins Júnior, 2013).

Em complemento, a Lei $\mathrm{n}^{\circ}$ 16.050, de 31 de julho de 2014, em seu Artigo 30, $\S 3^{\circ}$, lista os possíveis impactos negativos sentidos pelos moradores, como sendo:

- urbanístico, relativo à sobrecarga ou alteração imprópria da infraestrutura;

- poluição sonora;

- poluição relativa à emissão de gases prejudiciais ao meio ambiente e à saúde humana;

- poluição hídrica de efluentes líquidos incompatíveis;

- poluição por resíduos sólidos relativa à produção, manipulação ou estocagem;

- vibração por meio de uso de máquinas ou equipamentos;

- periculosidade em relação às atividades que apresentem risco ao meio ambiente e à saúde humana;

- geração de tráfego pela operação ou atração de veículos pesados.

$\mathrm{Na}$ mesma Lei, em seu Artigo 151, $\S 4^{\circ}$, o documento especifica os potenciais pontos a serem avaliados para se prevenir o chamado "impacto de vizinhança":

- adensamento populacional de moradores e usuários da área;

- demandas por serviços, equipamentos e infraestruturas urbanas e comunitárias;

- alterações no uso e ocupação do solo e seus efeitos na estrutura urbana;

- efeitos da valorização imobiliária no perfil socioeconômico da área e da população moradora e usuária;

- efeitos na valorização ou desvalorização imobiliária;

- geração de tráfego e de demandas por melhorias e complementações nos sistemas de transporte coletivo e de circulação não motorizada, em especial de bicicletas e pedestres;

- efeitos da volumetria do empreendimento;

- geração de poluição ambiental e sonora na área;

- águas superficiais e subterrâneas existentes na área;

- acúmulo de impactos urbanos, ambientais, socioeconômicos e culturais. 


\section{Análise Envoltória de Dados}

A Análise Envoltória de Dados (Data Envelopment Analysis - DEA), ou Teoria da Fronteira (Frontier Analysis), é um modelo matemático que utiliza a Pesquisa Operacional - PO para analisar sistemas complexos e dar instrumentos de otimização para uma possível tomada de decisão (Ferreira \& Gomes, 2009). Consiste em analisar a eficiência de um conjunto de unidades produtivas, baseado na comparação de suas relações entre insumos (inputs) e produtos (outputs) e construindo modelos matemáticos cuja distribuição da população não respeita parâmetros estatísticos, pode não ter relações funcionais entre si nem a mesma forma de medida. Na aplicação, avalia-se o desempenho relativo de uma população produtiva, onde existam múltiplos insumos e múltiplos produtos que vão gerar vários resultados.

O desenvolvimento do método teve início com a publicação do trabalho The Measurement of Productive Efficiency, em 1957, por Michael James Farrell (Ferreira \& Gomes, 2009; Farrell, 1957). Nele, o autor analisa o problema de se medir a eficiência produtiva de uma indústria somente do ponto de vista teórico econômico, e propõe uma forma de se avaliar fatores não ligados diretamente ao produto, mas que contribuem para a otimizar a função produção.

O modelo de Farrell (1957) limita-se à avaliação de apenas um produto como resultado da combinação de vários insumos, a mão de obra, o capital investido, a área ocupada e a matéria prima utilizada. Já o trabalho Measuring the efficiency of the decision making units, de Edwardo Lao Rhodes (Charnes et al., 1978), ampliou o método para aceitar várias entradas e várias saídas. Com isso, se consolidou como um método que utiliza o termo Decision Making Units - DMU para definir unidades tomadoras de decisão que promovam a transformação de insumos (inputs) em produtos (outputs) (Charnes et al., 1978; Banker et al., 1984; Smirlis et al., 2012).

\section{Eficiência e Benchmarking}

Segundo os princípios da Economia, o Produto $(q)$ é resultado da multiplicação entre os fatores de produção, chamados Insumos, que são: mão de obra $(N)$, capital $(K)$, área $(T)$ e matéria prima (Mp), como representado na Equação (1) (Mankiw, 2013).

$$
q=f(N, K, T, M p)
$$

O processo produtivo se baseia em transformar Insumos - inputs em Produtos outputs, sendo que, a razão entre os produtos e os insumos determina a produtividade do sistema. Portanto, a produtividade é relativa aos produtos e insumos avaliados, sendo maior quanto menor forem os insumos utilizados ou maiores os produtos resultantes (Slack et al., 2011).

A Análise Envoltória de Dados utiliza o conceito de eficiência como a maior produtividade medida entre um grupo de resultados avaliados, configurando uma fronteira de eficiência traçada pelos resultados das melhores relações entre produtos e insumos. A Figura 1 ilustra a comparação feita entre pela análise DEA indicando a fronteira de eficiência dentre os resultados das diversas DMU's (Banker et al., 1984).

No DEA, a eficiência compara o resultado das relações entre outputs e inputs de todas as DMU's, e identifica o benchmarking para cada DMU buscar atingir a eficiência. Em essência, as DMU's benchmarks são referência dentro de um grupo, e são definidas como objetivo para as outras alcançarem seu nível de insumos e produtos (Meza et al., 2005; Smirlis et al., 2012). 
Figura 1. Representação das fronteiras de eficiência e ineficiência na análise DEA

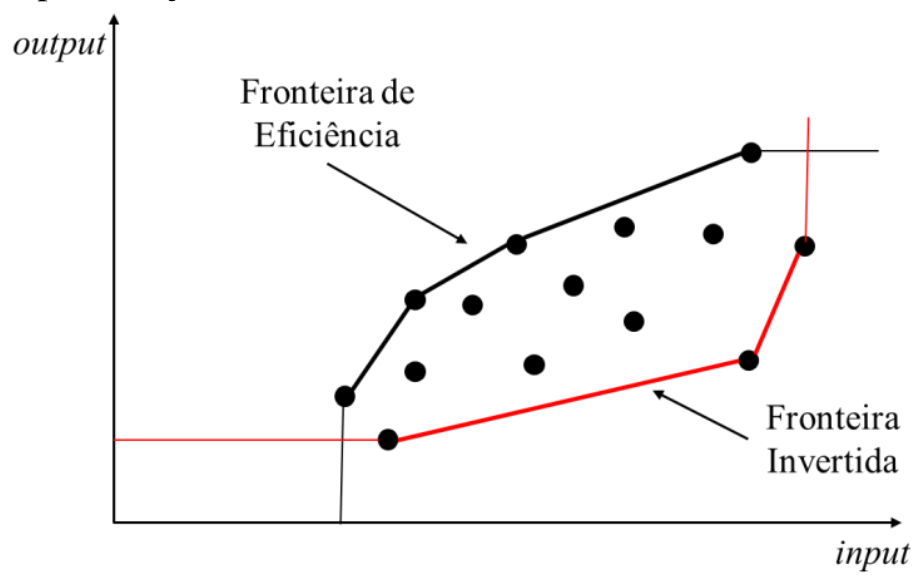

Fonte. elaborado pelos autores

\section{Modelos, Orientação e Fronteira Invertida}

O modelo matemático inicial de Farrell (1957) passou por atualizações para se configurar como a Análise Envoltória de Dados e, em especial, duas atualizações determinaram os modelos originais da ferramenta, o de retornos constantes de escala e o de retornos variáveis de escala. Para qualquer um dos modelos a otimização pode acontecer por duas perspectivas, a primeira fixando os outputs e minimizando os inputs, e a segunda fixando os inputs e maximizando os outputs (Ferreira \& Gomes, 2009; Charnes et al., 1978).

Modelo $C C R$ - com seu nome atribuído às iniciais dos autores Charnes, Cooper e Rhodes, também é conhecido como CRS (Constant Returns to Scale) pois prevê retornos constantes de escala, ou seja, para qualquer variação nos insumos (inputs) existe uma variação proporcional nos produtos (outputs) (Charnes et al., 1978).

Como uma otimização, o sistema prevê a utilização de pesos atribuídos aos inputs e outputs, o que inclui nas fórmulas as variáveis de decisão " $u$ " e " $v$ ", e, ainda, como o modelo é um problema de programação linear, o denominador da função objetivo deve corresponder a uma constante unitária, assim, são definidas as Equações (2) para orientação aos insumos e (3) aos produtos.

$$
\operatorname{Max} E f f_{0}=\sum_{j=1}^{s} u_{j} y_{j 0}
$$

Sujeito a:

$$
\begin{gathered}
\sum_{i=1}^{r} v_{i} x_{i k}=1 \\
\sum_{j=1}^{s} u_{j} y_{j k}-\sum_{i=1}^{r} v_{i} x_{i k} \leq 0, K \\
=1,2 \ldots, n \\
u_{j} \text { e } v_{i} \geq 0 \forall j, i \\
\operatorname{Min} E f f_{0}=\sum_{i=1}^{r} v_{i} x_{i 0}
\end{gathered}
$$


Sujeito a:

$$
\begin{gathered}
\sum_{i=1}^{r} u_{j} y_{j k}=1 \\
\sum_{i=1}^{r} v_{i} x_{i k}-\sum_{j=1}^{s} u_{j} y_{j k} \leq 0, K \\
=1,2 \ldots, n \\
u_{j} \text { e } v_{i} \geq 0 \quad \forall j, i
\end{gathered}
$$

Onde:

Eff $_{0}=$ eficiência da $\mathrm{DMU}_{0}$;

$\mathrm{u}_{\mathrm{j}}=$ pesos dos outputs, variável de decisão;

$\mathrm{v}_{\mathrm{i}}=$ pesos dos inputs, variável de decisão;

$\mathrm{y}_{\mathrm{jk}}=$ outputs j para a $\mathrm{DMU}_{\mathrm{k}}$;

$\mathrm{x}_{\mathrm{ik}}=$ inputs i para a $\mathrm{DMU}_{\mathrm{k}}$

$\mathrm{y}_{\mathrm{j} 0}=$ outputs $\mathrm{j}$ para a $\mathrm{DMU}_{0}$;

$\mathrm{x}_{\mathrm{i} 0}=$ inputs i para a $\mathrm{DMU}_{0}$.

Modelo $B C C$ - igualmente tem seu nome atribuído às iniciais dos autores Banker, Charnes e Cooper, também é conhecido como VRS (Variable Return to Scale) pois prevê retornos variáveis de escala, ou seja, para qualquer variação nos insumos (inputs) existe uma variação não proporcional dos produtos (outputs), podendo gerar retornos crescentes ou decrescentes de escala. A Equação (4) representa o modelo BCC orientado aos insumos e a Equação (5) orientado aos produtos (Banker et al., 1984).

Sujeito a:

$$
\operatorname{Max} \operatorname{Eff}_{0}=\sum_{j=1}^{s} u_{j} y_{j 0}+u_{*}
$$

$$
\begin{gathered}
\sum_{i=1}^{r} v_{i} x_{i 0}=1 \\
\sum_{j=1}^{s} u_{j} y_{j k}-\sum_{i=1}^{r} v_{i} x_{i k}+u_{*} \leq 0, K \\
=1,2 \ldots, n \\
u_{j} e v_{i} \geq 0 \quad \forall j, i \\
u_{*} \in R \\
\operatorname{Min}_{E f f_{0}}=\sum_{i=1}^{r} v_{i} x_{i 0}+v_{*}
\end{gathered}
$$

Sujeito a:

$$
\begin{gathered}
\sum_{j=1}^{s} u_{j} y_{j 0}=1 \\
\sum_{j=1}^{s} u_{j} y_{j k}-\sum_{i=1}^{r} v_{i} x_{i k}+v_{*} \leq 0, K \\
=1,2 \ldots, n
\end{gathered}
$$




$$
\begin{aligned}
u_{j} \text { e } v_{i} & \geq 0 \quad \forall j, i \\
v_{*} & \in R
\end{aligned}
$$

A utilização dos modelos DEA por vezes resultam um grande número de DMU's consideradas eficientes, inviabilizando a tomada de decisão. A técnica desenvolvida por Yamada et al. (1994) avalia também a ineficiência da unidade produtiva, construindo uma nova fronteira com as unidades mais ineficientes, o que seria o inverso do benchmarking. Com uma troca de posições, os inputs e os outputs do modelo original indicam a visão pessimista, conforme mostrado na Figura 1, que fecha um contorno de todos os resultados e demonstra os referenciais do melhor a ser seguido e do pior a ser evitado (Meza et al., 2005; Cooper, Seiford \& Zhu, 2011).

Nos casos em que um grande número de DMU's se mostra eficiente, a técnica de fronteira invertida contribui na escolha da melhor DMU, pois pondera entre as DMU's mais eficientes e as menos ineficientes.

\section{MÉTODO E COLETA DE DADOS}

Esta pesquisa se caracteriza como aplicada, pois procura produzir conhecimentos dirigidos à solução dos problemas levantados por meios experimentais, observadas as variações propostas pelo pesquisador. Tem abordagem quali-quantitativa, pois interpreta contextos não paramétricos e avalia o quanto eles impactam em seus objetivos. Para se atingir os objetivos, a pesquisa toma por base o estudo de caso da cidade de São Paulo, do qual são consultadas as Leis, registros e relatórios técnicos, de onde são definidas as variáveis que são manipuladas, a critério do pesquisador, para observação dos resultados (Severino, 2000).

Utiliza-se o método de Análise Envoltória de Dados para se avaliar a relação entre as sensações de bem-estar da população correspondentes ao serviço de TUC, ponderando entre o conforto das entregas dos produtos necessários (outputs) e o desconforto das incomodidades provocadas (inputs).

\section{Outputs - Produtos}

Os outputs, ou produtos, representam o resultado do processo produtivo que se deseja maximizar e, neste estudo, se baseia nas seis variáveis que caracterizam a escolha de um serviço de TUM (Ballou, 2006), baseadas em McGinnis (1990), sendo elas:

- Tarifas dos fretes;

- Confiabilidade;

- Tempo em trânsito;

- Perdas, danos, processamento das reclamações;

- Considerações de mercado sobre o embarcador;

- Considerações relativas aos transportadores.

Ao se avaliar o TUM, algumas das variáveis definidas por McGinnis (1990) não se aplicam, ou têm importância inexpressiva, como as "Perdas, danos, processamento das reclamações" e "Considerações de mercado sobre o embarcador". Assim, faz-se uma seleção de quais variáveis representam indicadores dos resultados esperados pelo cliente, que são:

- Custo/Preço - indicador da variável "Tarifas dos fretes" e relaciona o serviço do transportador ao preço final que é cobrado de seu cliente, ou o custo que o cliente tem em contratar o serviço. $\mathrm{O}$ valor, neste caso, espera-se que seja o 
menor possível, com a maior economia. Como referência é utilizado o valor do equipamento utilizado no serviço de transporte, quantificado em valores monetários do Brasil (Real).

- Agilidade - indicador da variável "Confiabilidade" e é definida pelo atendimento do tempo previsto para o transporte, envolvendo a velocidade desenvolvida e a rapidez dos serviços, gerando a confiabilidade no serviço de transporte. Mede-se o tempo esperando que seja o menor, pois assim será o mais ágil. Exclui-se, neste caso, o serviço de carga e descarga e avalia-se o tempo desenvolvido durante a operação.

- Capacidade de Carga - indicador da variável "Considerações relativas aos transportadores" e refere-se à característica própria do transportador, definida por sua capacidade em carregar determinado volume ou peso de carga. A capacidade de carga é o referencial mais característico do transportador, o qual é melhor se tiver uma maior capacidade de carga. Baseia-se nas características dos fabricantes dos veículos transportadores de mercadorias, ou de regras legais que limitem suas operações, medida em $\mathrm{Kg}$ (quilograma).

- Agilidade na Carga/Descarga - indicador da variável "Tempo em trânsito" e representa a rapidez, ou agilidade, com que se realizam as operações específicas de carga e descarga, para as quais, o menor tempo utilizado representa um serviço de transporte melhor.

Portanto, são considerados quatro outputs a serem avaliados mediante ajustes para que respeitem a regra de maximização dos valores.

No caso da "Capacidade de Carga", o maior valor é o melhor resultado, respeitando a regra da produtividade de se "fazer mais com menos", porém, no caso do "Custo/Preço", "Agilidade" e "Agilidade na Carga/Descarga", quanto menor forem os valores, melhor é o resultado. Assim, nesses casos de output, seus dados serão submetidos a uma normalização linear com inversão dos pesos, fazendo com que o produto com maior valor tenha menor peso.

É feita a normalização, ordenando-se as variáveis da menor para a maior, adotando o maior valor como referência e ponderando o quanto as variáveis intermediárias estão distantes desse valor. Dessa forma o maior assume o valor mais baixo, e o menor assume o valor mais alto.

\section{Inputs - Insumos}

Segundo Slack et al. (2011), os inputs representam tudo aquilo que é necessário para se produzir algo, também denominados insumos, que representam matérias primas, equipamentos, mão de obra, capital, e tudo que seja necessário para se produzir (Mankiw, 2013).

Normalmente a definição de insumo está relacionado ao processo produtivo de Slack et al. (2011), voltado a tudo aquilo que se consome para se produzir algo, na busca da menor utilização de insumos para se produzir o máximo de produtos. Nesta pesquisa, os insumos são representados pela cessão de direito de uso dos recursos estruturais de uma cidade pelo TUM, com o objetivo de utilizar o mínimo de recursos e gerar o mínimo de impactos, segundo aqueles identificados no PDE do Município de São Paulo (São Paulo, 2014).

O PDE-SP determina limites de interferência de quaisquer agentes no ambiente urbano. Assim, qualquer obra, negócio, morador, transeunte, na região urbana da 
cidade, se obriga a respeitar limites de ruídos, emissão de gases, vibração, poluição ou qualquer outro desgaste para o BEP. O documento lista os possíveis geradores de desconfortos, aqui citados como:

- sobrecarga ou alteração imprópria da infraestrutura existente - existência de um número de usuários superior àquele previsto e autorizado;

- poluição sonora - emissão de ruídos em níveis superiores aos indicados;

- emissão de gases nocivos ao meio ambiente e ao ser humano - emissão gases prejudiciais à saúde e meio ambiente;

- poluição hídrica - emissão de efluentes líquidos incompatíveis;

- poluição relativa à produção, manipulação ou estocagem - emissão de poeira, fuligem, material particulado, resultados dos processos de produção e logística dos produtos;

- vibração pelo uso de máquinas ou equipamentos - vibração gerada pelo simples funcionamento de veículos e equipamentos pesados;

- periculosidade de atividades sobre o meio ambiente e as pessoas - atenção gerada pela iminência de potencial acidente prejudicial ao meio ambiente ou às pessoas;

- geração de tráfego pela operação ou atração de veículos pesados - aumento do número de veículos pesados transportando mercadorias no ambiente urbano.

$\mathrm{O}$ mesmo documento também faz referência a pontos avaliados como de "impactos de vizinhança", aqui citados como:

- adensamento populacional - aumento de habitantes por metro quadrado nas regiões;

- demandas por serviços, equipamentos e infraestruturas urbanas e comunitárias necessidade de serviços públicos característicos de uma cidade;

- alterações indevidas no uso e ocupação do solo - utilização inadequada dos espaços urbanos segundo o que determina o PDE;

- efeitos da valorização imobiliária no perfil socioeconômico da área - áreas supervalorizadas, incompatível com o perfil socioeconômico da população;

- efeitos na valorização ou desvalorização imobiliária - valorização ou desvalorização imobiliária altera as obrigações tributárias impostas pelo estado;

- geração de tráfego motorizado ou não - incentivo à geração de viagens e a utilização de veículos de transporte;

- efeitos da volumetria do empreendimento - empreendimentos extremamente ocupados gerando excesso de usuários;

- geração de poluição ambiental e sonora - emissão de gases, poeira, material particulado, ruído, incompatíveis com o ambiente;

- águas superficiais e subterrâneas existentes na área - condicionando o perigo de enchentes;

- acúmulo de impactos urbanos, ambientais, socioeconômicos e culturais relacionando a associação de vários dos impactos relatados anteriormente.

Dentre todos estes potenciais fatores geradores de impactos negativos aos cidadãos, alguns são desconsiderados por não serem influenciados pelo transporte, ou têm essa influência demasiadamente indireta, ou ainda, são tão genéricos para o TUM que não há motivo de serem avaliados. Dos itens considerados, esta pesquisa desenvolve a análise de sete inputs identificados como depreciadores do BEP urbana, são eles: 
- Adensamento populacional - mede o número de pessoas que habitam, trabalham ou têm alguma relação com determinada região, com base nos dados disponibilizados em Geosampa (2019).

- Adensamento de negócios - demonstra o número de negócios instalados e também se baseia em dados obtidos em Geosampa (2019).

- Adensamento Veicular - avalia o número de veículos que circulam na cidade de São Paulo, com dados obtidos do relatório "Emissões veiculares no estado de São Paulo 2016" (Companhia Ambiental do Estado de São Paulo - CETESB, 2016).

- Poluição Sonora - avalia a intensidade de ruídos emitidos e adota a potência do motor dos veículos avaliados como indicador para quantificar o nível de ruído, para os quais, quanto maior a potência, maior o ruído gerado. São utilizados os dados da ficha técnica do fabricante dos veículos considerados.

- Poluição Ambiental - avalia o quanto é gerado de agressões ao meio ambiente, como a emissão de gases, poeira, material particulado, ruído, incompatíveis com o ambiente, porém, neste caso excetua-se a poluição sonora que já é avaliada individualmente. Nesta avaliação são utilizados dados coletados do Inventario de Emissões por Veículos do Ministério do Meio Ambiente (Brasil, 2014).

- Vibração - avalia a vibração gerada pelo simples movimento de veículos e funcionamento de equipamentos pesados a partir de seu Peso Bruto Total. São avaliados dados da ficha técnica do fabricante dos veículos considerados.

- Periculosidade - é avaliada a atenção necessária devido à iminência de potencial acidente prejudicial ao meio ambiente ou às pessoas. São utilizados dados publicados do Seguro de Trânsito (Danos Pessoais por Veículos Automotores Terrestres - DPVAT, 2019) para cada veículo estudado.

\section{Unidades Tomadoras de Decisão - DMU's}

A pesquisa analisa como as Unidades Tomadores de Decisão - DMU's os seguintes veículos:

- Bicicleta - Silva (2012) define que as bicicletas são veículos não motorizados, que podem ser utilizadas para TUM, são mais ágeis que os demais e necessitam de um vão menor para circulação, representando uma alternativa para a entrega de mercadorias em áreas onde a circulação e vagas para estacionamento de veículos têm limitações. A pesquisa adota o modelo Urbam oferecido pelo fabricante Caloi (2019).

- Motocicleta - Roqueiro (2014) afirma que a motocicleta é uma boa alternativa para o TUM por ter dimensões reduzidas e ocupar pouco espaço nas vias e estacionamentos, e, ainda, possuem um motor a combustão que tem maior eficiência energética que os carros, apesar de apresentar desvantagens pela dependência das condições climáticas e sua fragilidade no caso de acidentes. A referência é a motocicleta modelo CG 160 Cargo, do fabricante Honda (2019).

- Veículo utilitário de pequeno porte - o Código de Trânsito Brasileiro (Brasil, 1997) define como utilitário o veículo que tem uso misto entre o transporte de passageiros e carga, e o Manual de Projeto de Interseções, elaborado pelo Departamento Nacional de Infraestrutura de Transportes - DNIT (2005), qualifica veículos comerciais leves como veículos pequenos, modelos Pick-up, Furgão ou Jeep. Nesta pesquisa, o veículo utilitário de pequeno porte corresponde a veículos com dimensões próximas às de um modelo de passeio, 
categorizados pelos fabricantes como comerciais. O representante estudado é o modelo Fiorino do fabricante Fiat (2019).

- Veículo urbano de carga - São Paulo (2014) define o veículo urbano de carga VUC como um caminhão de pequeno porte, com dimensões e características adequadas à distribuição de mercadorias e abastecimento no meio urbano, propiciando redução no conflito com pedestres, outros veículos não motorizados, de transporte coletivo e demais veículos, e que devem observar condições adequadas quanto à emissão de poluentes. Deve ter, no máximo, a largura de 2,20m (dois metros e vinte centímetros) e o comprimento de 7,20m (sete metros e vinte centímetros), com data de fabricação a partir de janeiro de 2005. O modelo adotado na pesquisa é o Iveco Daily City do fabricante Iveco (2019).

- Caminhão - Segundo o que conceitua o Conselho Nacional de Trânsito CONTRAN (2008), caminhão é todo veículo automotor destinado ao transporte de carga, com PBT (peso total bruto) acima de 3.500 quilogramas, podendo tracionar ou arrastar outro veículo dentro de sua capacidade máxima. A pesquisa considera caminhões com PBT próximo a 10.000 quilogramas, sendo estudado o modelo Caminhão A10000 do fabricante Agrale (2019).

São considerados os dados característicos de cada DMU aqueles indicados nas fichas técnicas de cada fabricante, os quais representam os vários modelos próximos do tipo de veículo adotado.

\section{Quadro de Produtos e Insumos}

Os produtos, ou outputs avaliados são:

- Custo/Preço - valores de mercado dos veículos na unidade de medida monetária $\mathrm{R} \$$ (Reais), considerando-se o valor encontrado em sites específicos dos fabricantes ou do comércio.

- Agilidade - o volume ocupado pelo veículo (largura x comprimento x altura) como determinante da facilidade com que ele vence as dificuldades no tráfego urbano, já que a velocidade máxima das vias é determinada por lei, e o volume de veículos transitando é que determina a velocidade média praticada.

- Capacidade de Carga - os volumes de carga útil (mais carroceria, se for o caso) que se pode transportar.

- Agilidade na Carga/Descarga - a restrição predominante no ambiente urbano é o espaço, aqui definido pela escassez de vagas para estacionamento, carga e descarga. A ocupação de território pelo veículo em suas operações caracteriza-se como uma conquista, e ela é facilitada pela área (largura x comprimento) que ele ocupa.

Com os valores normalizados, conforme descrito, a Tabela 1 apresenta os outputs utilizados. 
Tabela 1. Quadro de outputs utilizados

\begin{tabular}{lllll}
\hline Veículo & Custo & Agilidade & $\begin{array}{l}\text { Capacidade } \\
\text { Carga }\end{array}$ & $\begin{array}{l}\text { Agilidade } \\
\text { Carga/ } \\
\text { Descarga }\end{array}$ \\
\hline Bicicleta & $170.887,00$ & 36,07 & 5,00 & 15,03 \\
Motocicleta & $162.259,00$ & 35,54 & 20,00 & 14,57 \\
V. U. P. P. & $106.996,00$ & 21,26 & 650,00 & 7,72 \\
VUC & $63.986,00$ & 9,72 & $1.800,00$ & 3,86 \\
Caminhão & $1.099,00$ & 1,23 & $6.740,00$ & 1,14
\end{tabular}

Fonte. elaborado pelos autores

Como insumos, ou inputs, são avaliados:

- Adensamento populacional - são utilizados dados em Instituto Brasileiro de Geografia e Estatística - IBGE (2019) sobre a densidade demográfica do município de São Paulo em 7.398,26 hab/ $/ \mathrm{km}^{2}$. Na pesquisa interessa avaliar o impacto relativo de uma DMU frente à população, assim, calcula-se o input como a razão entre a área ocupada pelo veículo e a densidade demográfica, multiplicando-se o resultado por 1.000 para melhor visualização dos resultados.

- Adensamento de negócios - também com dados em IBGE (2019), obtém-se o número de 535.594 empresas atuantes no município de São Paulo, gerando movimento de pessoas e produtos e potencializando o transporte de cargas nas áreas urbanas. Na mesma lógica já utilizada, a pesquisa calcula o input como a razão entre a área ocupada pelo veículo e o número de negócios existentes na região, multiplicando-se o resultado por 1.000.000 para melhor visualização dos resultados.

- Adensamento Veicular - com dados coletados em IBGE (2019) para a frota de veículos e, em Companhia de Engenharia de Tráfego de São Paulo - CET (2018) para o caso da bicicleta. Aqui também, a pesquisa avalia a área ocupada pelo veículo transportador como numerador da razão entre sua área e o número de veículos, multiplicando-se o resultado por 1.000 .000 para melhor visualização dos resultados.

- Poluição Sonora - parte-se do princípio de que os ruídos avaliados são o resultado da motorização dos veículos, assim, utiliza-se como determinante da poluição sonora a potência dos motores de cada veículo transportador, disponíveis em sua ficha técnica.

- Poluição Ambiental - em Brasil (2014), o Inventário Nacional De Emissões Atmosféricas apresenta a emissão de CO (monóxido de carbono) por tipo de veículo, refletindo o quanto a frota de cada tipo de veículo estudado já contribui para a poluição ambiental.

- Vibração - o peso bruto total é diretamente responsável pelas vibrações sentidas nas vias e os valores são indicados nas fichas técnicas de cada veículo.

- Periculosidade - para dar dimensão ao perigo inerente ao uso de cada veículo estudado é avaliado o histórico de acidentes do Relatório Estatístico DPVAT do $1^{\circ}$ Semestre-2019 (DPVAT, 2019), de onde são coletados os valores da quantidade de indenizações para motocicletas e caminhões. Para bicicletas não há registro e a pesquisa as considera completamente seguras. Para os utilitários é 
utilizado o valor equivalente ao veículo VAN, e para o VUC equivalente ao veículo caminhão.

O quadro de inputs é apresentado na Tabela 2.

Tabela 2. Quadro de inputs utilizados

\begin{tabular}{|c|c|c|c|c|c|c|c|}
\hline Veículo & População & Neg. & Veículos & $\begin{array}{l}\text { P. } \\
\text { Sonora }\end{array}$ & $\begin{array}{l}\text { P. } \\
\text { Ambiental }\end{array}$ & Vibr. & Pericul. \\
\hline Bicicleta & 153,75 & 2,12 & 20,11 & 0,00 & 0,00 & 21,80 & 0,00 \\
\hline Motocicleta & 216,27 & 2,99 & 1,66 & 14,90 & $406.768,00$ & 119,00 & $119.055,00$ \\
\hline V. U. P. P. & $1.141,29$ & 15,76 & 63,46 & 85,00 & $330.765,00$ & $1.768,00$ & $2.674,00$ \\
\hline VUC & $1.663,35$ & 22,98 & 24,74 & 130,00 & $42.457,00$ & $3.500,00$ & $5.939,00$ \\
\hline Caminhão & $2.031,48$ & 28,06 & 113,53 & 162,00 & $18.266,00$ & $\begin{array}{l}10.000,0 \\
0\end{array}$ & $5.939,00$ \\
\hline
\end{tabular}

Fonte. elaborado pelos autores

\section{APRESENTAÇÃO E ANÁLISES DE RESULTADOS}

Os dados das DMU's, outputs e inputs, são alimentados no software SIAD configurado para realizar a análise segundo o modelo $\mathrm{BCC}$, pois não existe proporcionalidade entre os valores de input e output, e com orientação ao input, pois se busca minimizar os impactos causados ao BEP sem aumento na carga de cada veículo transportador. Como forma de acentuar as diferenças entre os resultados de eficiência calculados utiliza-se o recurso Fronteira Invertida, e o resultado é apresentado na Figura 2 .

Figura 2. Resultado apresentado no software SIAD

\begin{tabular}{|l|c|c|c|c|}
\hline & Padrão & Invertida & Composta & Composta* \\
\hline bicicleta & 1,000000 & 1,000000 & 0,500000 & 1,000000 \\
\hline motocicleta & 1,000000 & 1,000014 & 0,499993 & 0,999986 \\
\hline v.u.p.p. & 0,552826 & 1,000296 & 0,276265 & 0,552530 \\
\hline VUC & 1,000000 & 1,000001 & 0,499999 & 0,999999 \\
\hline caminhão & 1,000000 & 1,000037 & 0,499982 & 0,999963 \\
\hline
\end{tabular}

Fonte. elaborado pelos autores com dados do SIAD

A coluna Composta mostra a média entre os modelos de eficiência e de ineficiência, conforme demonstrado em Meza et al. (2005). Como mostra a Equação (6), o cálculo determina que a Eficiência Composta é igual à média entre a Eficiência Padrão (otimista) e a subtração da Eficiência Invertida (pessimista) de uma unidade.

$$
E f_{\text {composta }}=\frac{E f_{\text {padrão }}+\left(1-E f_{\text {invertida }}\right)}{2}
$$

Desta forma se obtém valores que hierarquizam as DMU's na relação de maior eficiência e menor ineficiência na seguinte configuração: 
1. Bicicleta

2. Veículo Urbano de Carga

3. Motocicleta

4. Caminhão

5. Utilitário de Pequeno Porte

A Equação (7) demonstra o cálculo da coluna Eficiência Composta* apresentada no SIAD, que representa a normalização dos valores de Eficiência Composta.

Eficiência Composta* = Eficiência Composta / Max (Eficiência (7)

Composta)

O resultado reforça que, apesar da mínima capacidade de carga, a bicicleta possui expressiva vantagem por ser um veículo não motorizado, assim, sua eficiência em não incomodar o ambiente urbano é significativa, sendo considerada o benchmarking desta pesquisa.

Levando-se em conta o volume de carga transportado, o veículo que alcança a segunda posição no ranking de eficiência prestigia a lei que valoriza a utilização do Veículo Urbano de Carga - VUC (São Paulo, 2014) nas zonas de restrição ao tráfego da cidade de São Paulo.

Apesar da extrema agilidade, a motocicleta surge atrás dos VUCs na ordem de eficiência, já que, além do reduzido volume de carga que transporta em cada viagem, não fica muito atrás dos veículos de quatro rodas nos níveis de impactos negativos ao BEP que causam, além de ser o veículo campeão distante em periculosidade.

Já o caminhão, que aparentemente seria o campeão de impactos negativos ao BEP, tem em sua capacidade de carga a compensação pelos transtornos que causa. A viabilidade econômica o define como melhor opção para a logística urbana, porém os fatores de sustentabilidade têm criado dificuldades no mundo todo sobre sua utilização nesse ambiente.

O veículo menos eficiente é o utilitário de pequeno porte, o qual surpreende pela posição, já que sua utilização se difunde pela composição de capacidade de carga e a agilidade que oferece, pois são veículos com dimensões reduzidas que transportam um volume de carga considerável para o ambiente urbano.

\section{CONSIDERAÇÕES FINAIS}

A pesquisa alcança seu objetivo avaliar a eficiência dos veículos usados no TUM na cidade de São Paulo, segundo os fatores que impactam negativamente no BEP. O PDE da cidade de São Paulo, assim como os dados disponibilizados no portal Geosampa demonstram coerência entre os fatores avaliados e os resultados obtidos. Por fim, a Análise Envoltória de Dados - DEA, processada no software SIAD, demonstra capacidade de produzir resultados hierarquizados a partir de dados não paramétricos.

Os resultados apresentados são coerentes e projetam opções de decisão factíveis, plenamente possíveis de serem praticadas por empresas ou o Poder Público em suas estratégias de gestão, especialmente no caso da utilização de bicicletas como a opção não motorizada para distribuição de mercadorias. Atenção especial deve ser dada para o caso do VUC, que é o veículo motorizado mais eficiente da pesquisa e têm sua utilização definida por lei de zoneamento da cidade de São Paulo.

A pesquisa mostra avanço na utilização da ferramenta de Análise Envoltória de Dados - DEA para avaliar a eficiência no nível de sensações humanas, na abordagem de 
fatores urbanísticos que influenciam a logística urbana e na avaliação da eficiência de veículos não convencionais utilizados no TUM, como a bicicleta.

Pesquisas futuras podem evoluir a perspectiva apresentada, diversificando nas opções de veículos utilizados, na interpretação das incomodidades e nas exigências atuais dos usuários do transporte urbano de mercadorias.

\section{REFERÊNCIAS}

Agrale (2019). Ficha Técnica do Caminhão Agrale A10000. Recuperado em 20 de março de 2020, de: https://www.agrale.com.br /pt/caminhoes-leves/caminhaoagrale-a10000-1.

Araújo Junior, M. E. (2005). Algumas considerações sobre o Plano Diretor dos municípios e sua importância no processo de construção da cidadania e da democracia. Revista do Direito Público, 1(1), 45-62.

Ballou, R. H. (2006). Gerenciamento da Cadeia de Suprimentos / Logística Empresarial (5 $5^{\mathrm{a}}$ Ed.). Porto Alegre: Bookman.

Banker, R. D., Charnes, A., Cooper, W. W. (1984). Some models for estimating technical and scale inefficiencies in data envelopment analysis. Management science, 30(9), 1078-1092.

Brasil (1997). Código de Trânsito Brasileiro. Presidência da República. Recuperado em 20 de março de 2020, de: http://www.planalto.gov.br/ccivil_03/leis/19503.htm.

Brasil (2001). Lei n. 10.257, de 10 de julho de 2001. Regulamenta os arts. 182 e 183 da Constituição Federal, estabelece diretrizes gerais da política urbana e dá outras providências. Estatuto da Cidade. Presidência da República. Recuperado em 20 de março de 2020, de: http://www.planalto.gov.br/ccivil_03/leis/leis_2001/110257.htm.

Brasil (2014). Inventário nacional de emissões atmosféricas por veículos automotores rodoviários. Ministério do Meio Ambiente. Recuperado em 20 de março de 2020, de:

http://www.mma.gov.br/images/arquivo/80060/Inventario_de_Emissoes_por_Vei culos_Rodoviarios_2013.pdf.

Brito, F., \& de Pinho, B. A. (2016). Distribuição espacial da população, urbanização e migrações internas no Brasil. Anais, ABEP Associação Brasileira de Estudos Populacionais, 1-21.

Caloi (2019). Manual e Ficha Técnica Caloi Urbam. Manaus. Recuparado em: https://www.caloi.com/urbam-007983-19003_pai/p\#specification

CETESB - Companhia Ambiental do Estado de São Paulo (2016). Emissões veiculares no estado de São Paulo 2016. Cetesb, São Paulo. Recuperado em 20 de março de 2020, de: https://cetesb.sp.gov.br/veicular/wp- 
content/uploads/sites/6/2013/12/Relatorio-emissoes-Veiculares-2015-v4_.pdf

CET - Companhia de Engenharia de Tráfego de São Paulo (2018). Pesquisa de Monitoração da Mobilidade. Mobilidade no Sistema Viário Principal - MSVP 2017. Recuperado em 20 de março de 2020, de: http://www.cetsp.com.br/media/714822/msvp-2017-volume-e-velocidade.pdf

Charnes, A., Cooper, W. W., Rhodes, E. (1978). Measuring the efficiency of decision making units. European journal of operational research, 2(6), 429-444.

Cintra, M. (2014). Os Custos do Congestionamento na Cidade de São Paulo. Textos para discussão. Escola de Economia da Fundação Getúlio Vargas - EESP. Recuperado em 20 de março de 2020, de: http://bibliotecadigital.fgv.br/dspace/bitstream/handle/10438/11576/TD\%20356\% 20-\%20Marcos\%20Cintra.pdf?sequence=1\&is Allowed=y.

CONTRAN - Conselho Nacional de Trânsito (2008) Disciplina a inscrição de pesos $e$ capacidades em veículos de tração, de carga e de transporte coletivo de passageiros, de acordo com o Código de Trânsito Brasileiro. CONTRAN, Brasília. Recuperado em 20 de março de 2020, de: www.der.pr.gov.br/arquivos/File/RESOLUCAOCONTRAN29008.pdf

Cooper, W. W., Seiford, L. M., \& Zhu, J. (2011) Handbook on data envelopment analysis, 164 ( $2^{\mathrm{a}}$ Ed.). Springer.

DNIT - Departamento Nacional de Infraestrutura de Transportes (2005) Manual de Projeto de Interseções, Capítulo 7. Recuperado em 20 de março de 2020, de: http://www1.dnit.gov.br/ipr_new/..\%5Carquivos_internet\%5Cipr\%5Cipr_new\%5 Cmanuais\%5CMANUAL_DE_PROJETO_DE_INTERSECOES_Versao_Final.p df

Dorneles, A. C. B. (2015) O zoneamento e sua importância como um instrumento de planejamento urbano. Cadernos da Escola de Direito e Relações Internacionais, 2(13).

DPVAT - Danos Pessoais por Veículos Automotores Terrestres (2019) Seguradora Líder - DPVAT. Relatório Estatístico DPVAT $1^{\circ}$ Semestre-2019. Recuperado em 20 de março de 2020, de: https://www.seguradoralider.com.br/Documents/boletim-estatistico/RelatorioEstatistico-1-Semestre-2019.pdf

Dutra, N. G. S. (2004) O Enfoque de "City Logistic" na Distribuição Urbana de Encomendas. Tese de Doutorado apresentada ao Curso de Engenharia de Produção da Universidade Federal de Santa Catarina, Florianópolis.

Farrell, M. J. (1957) The measurement of productive efficiency. Journal of the Royal Statistical Society: Series A (General), 120(3), 253-281. 
Ferreira, C. M. de C.; Gomes, A. P. (2009) Introdução à análise envoltória de dados: teoria, modelos e aplicações. Viçosa: Editora da Universidade Federal de Viçosa.

Fiat (2019) Ficha Técnica Fiorino 1.4 Evo Flex Manual. Recuperado em 20 de março de 2020, de: https://fiorino.fiat.com.br/

Gammelgaard, B. (2015) The emergence of city logistics: the case of Copenhagen's Citylogistik-kbh. International Journal of Physical Distribution \& Logistics Management, 45(4), 333-351.

Geosampa (2019) Mapa Digital da Cidade de São Paulo. Prefeitura de São Paulo. Recuperado em 20 de março de 2020, de: http://geosampa.prefeitura.sp.gov.br

Honda (2019) Ficha Técnica CG 160 Cargo. Manaus. Recuperado em 20 de março de 2020, de: https://www.honda.com.br/motos/cg-160-cargo

IBGE - Instituto Brasileiro de Geografia e Estatística (2019) Sistema agregador de informações do IBGE sobre os municípios e estados do Brasil. Recuperado em 20 de março de 2020, de: https://cidades.ibge.gov.br/ brasil/sp/sao-paulo/panorama

Iveco (2019) Ficha Técnica Iveco Daily. Recuperado em 20 de março de 2020, de: https://www.ivecodaily.com.br/

Mankiw, N. G. (2013) Princípios de Microeconomia (6 ${ }^{\mathrm{a}}$ Ed.) (Hastings, A.V., Trad.). São Paulo: Editora Cengage Learning.

Martins Júnior, O. P. (2013) Os fundamentos de gestão do espaço urbano para a promoção da função socioambiental da cidade: o caso de Goiânia. Tese de Doutorado apresentada ao Programa de Pós-Graduação em Ciências Ambientais da Universidade Federal de Goiás, Goiânia.

Mcginnis, M. A. (1990) The relative importance of cost and service in freight transportation choice: before and after deregulation. Transportation Journal, 1219.

Meza, L. A., Biondi Neto, L., Mello, J. C. C. B. S., Gomes, E. G. (2005) ISYDSIntegrated System for Decision Support (SIAD-Sistema Integrado de Apoio à Decisão): a software package for data envelopment analysis model. Pesquisa Operacional, 25(3), 493-503.

Ogden, K. W. (1992) Urban goods movement: a guide to policy and planning. New York: Ashgate Publishing.

Roqueiro, N. (2014) Propulsor híbrido para veículo urbano leve. In: D’agosto, M. A.; Jacques, L. C. A.; Oliveira, C. M. Transportes em Perspectiva: Uma contribuição dos pesquisadores brasileiros para o futuro dos transportes, 23(1). Rio de Janeiro: ANPET 311-322. 
São Paulo (Cidade) (2014) Lei $n^{\circ}$ 16.050/2014 de 31 de julho de 2014. Política de Desenvolvimento Urbano e o Plano Diretor Estratégico do Município de São Paulo e revoga a Lei $n^{o}$ 13.430/2002. Diário Oficial da Cidade de São Paulo, São Paulo.

Severino, A. J. (2000). Metodologia do trabalho científico. São Paulo: Ed Cortez.

Silva, R. C. (2012) Contribuição ao planejamento do transporte urbano de carga pela análise física do espaço urbano: estudo da área da rua do Catete e largo do Machado no Rio de Janeiro. Dissertação de mestrado apresentada ao Curso de Pós-Graduação em Engenharia de Transportes, PET/Coppe/UFRJ, Rio de Janeiro.

Slack, N.; Chambers, S.; Johnston, R. (2011) Administração da produção (Brandão, A.B., Trad.). São Paulo: Editora Atlas.

Smirlis, Y. G., Zeimpekis, V., Kaimakamis, G. (2012) Data envelopment analysis models to support the selection of vehicle routing software for city logistics operations. Operational Research, 12(3), 399-420.

Taniguchi, E; Thompson, R.G.; Yamada, T; Van Duin, J.H.R. (2001) City Logistics: Network Modelling and Intelligent Transport Systems. Pergamon Press.

Taylor, F. W. (2011) Princípios da Administração Científica ( $8^{\mathrm{a}}$ Ed.) (Ramos, A.V., Trad.). São Paulo: Editora Atlas.

Yamada, Y.; Matui, T.; Sugiyama, M. (1994) New analysis of efficiency based on DEA. Journal of the Operations Research Society of Japan, 37(2), 158-167. 